\title{
Recruiting fathers for parenting research using online advertising campaigns: Evidence from an Australian study
}

Liana S. Leach $(\mathrm{PhD} \text {, Senior Research Fellow })^{1}$, Shannon Bennetts (PhD, Postdoctoral Researcher) ${ }^{2}$, Rebecca Giallo (PhD, Associate Professor, Clinical Psychologist) ${ }^{3}$, Amanda Cooklin (PhD, Senior Research Fellow ${ }^{2}$

${ }^{1}$ National Centre for Epidemiology and Population Health, Research School of Population Health, The Australian National University, Canberra, Australia.

${ }^{2}$ Judith Lumley Centre, La Trobe University, Melbourne, Victoria, Australia

${ }^{3}$ Murdoch Childrens Research Institute, Melbourne, Victoria, Australia

Running title: Fathers are under-representing in parenting research.

Word count: 2727 (excluding abstract and references), 14 pages, 1 Table.

*Corresponding Author: Liana Leach. National Centre for Epidemiology and Population Health (NCEPH), Research School of Population Health, Building 62, The Australian National University, Acton, 2601, Australia. Tel: +61 2 61259725. Email:

Liana.Leach@anu.edu.au

This is the author manuscript accepted for publication and has undergone full peer review but has not been through the copyediting, typesetting, pagination and proofreading process, which may lead to differences between this version and the Version of Record. Please cite this article as doi: $10.1111 /$ cch.12698

This article is protected by copyright. All rights reserved. 
Ethical approval to conduct this study was granted by La Trobe University College of Science Health and Engineering Human Ethics Sub-Committee (SHE-CHESC Reference number: S16-112; 27/07/2016).

\begin{abstract}
Background: Fathers are under-represented in parenting and child health research. Given there is a strong link between fathers' parenting behaviour and children's wellbeing there is a need to find ways to engage fathers more consistently. The current short report provides information and learnings about recruiting fathers online using social media. Results are drawn from an Australian study that aimed to recruit roughly equal numbers of mothers and fathers to participate in a survey about employment, parenting and health, using online advertising.
\end{abstract}

Methods: First, a series of five Facebook advertising campaigns were run, aimed at 'parents' generally (i.e. gender-neutral). A lack of recruited fathers prompted a second series of six Facebook campaigns aimed solely at fathers. All campaigns targeted employed adult parents of children ( $\leq 18$ years) in Australia using Facebook's 'Adverts Manager'.

Results: The 11 campaigns recruited a total of 1,468 fathers. The vast majority of these fathers were recruited using the advertisements specifically aimed at fathers $(n=1,441)$. Gender-neutral campaigns inviting and selecting 'parents' to participate in the study overwhelmingly yielded samples of mothers. Similarly, advertisements inviting both 'mums and dads' resulted in very low recruitment of fathers.

Conclusions: The extremely low numbers of fathers recruited using the gender-neutral 'parent-focused' campaigns was unexpected. Potential reasons for this include low engagement with gender-neutral parenting terms, and/or that mothers were disproportionally exposed to the Facebook advertisements. These learnings suggest that father-focused recruitment is required to target and engage fathers in parenting research and services. 
Keywords: Australia; Father; Parent; Engagement; Research; Online; Gender

\section{Key messages}

- Fathers were not successfully recruited using the gender-neutral 'parent-focused' online advertising campaigns.

- There is a need for father-focused recruitment to target and engage fathers in research about parenting, care and family health.

- Father-focused online recruitment demonstrates good feasibility to recruit fathers for parenting research (i.e. time efficient and low-cost), but researchers may have limited control over sample reach/exposure.

\section{Introduction}

There is a growing body of evidence attesting to the contribution of fathers' health, involvement and parenting behaviour to their children's health and wellbeing (Flouri \& Buchanan, 2003; Morgan et al., 2011; Sarkadi, Kristiansson, Oberklaid, \& Bremberg, 2008). The value and importance of fathers' engagement in their children's lives has been reflected by increased calls for father-inclusive practice in perinatal, child, family and parenting services (Berlyn, Wise, \& Soriano, 2008). More recently, there has been recognition of the

This article is protected by copyright. All rights reserved. 
need for fathers' access to flexible work arrangements to allow for opportunities to care for their children (Gatrell, Burnett, Cooper, \& Sparrow, 2015). Despite the appeals for services to be more inclusive of fathers, gender disparities in uptake of perinatal, early childhood and parenting services persist - with fathers' participation generally low compared to mothers (Widarsson, Engström, Tydén, Lundberg, \& Hammar, 2015). Social and structural barriers to fathers' participation in services include stigma around masculine norms, feelings of exclusion (i.e. mother-centric focus in services), and clashes with employment responsibilities (Giallo, Dunning, \& Gent, 2017; Panter-Brick et al., 2014; Rominov, Giallo, Pilkington, \& Whelan, 2017). Many of these same barriers are also constraints to fathers' participation in parenting research. Fathers' participation and adequate representation in research is critical to ensure that their voices and needs are heard, and that the evidence to inform effective father-inclusive practices is generated. This paper addresses this issue, contributing valuable evidence about effective ways to engage contemporary fathers in parenting research.

It is well recognised that men are minimally engaged in social and health research (Davison, Charles, Khandpur, \& Nelson, 2017); including research about experiences of parenthood (Cabrera, Volling, \& Barr, 2018). In a review of fathers' involvement in developmental and pediatric psychology research, $48 \%$ of the 726 studies reviewed included mothers only, compared to just $2 \%$ with fathers only (Phares et al., 2005). A further $22 \%$ analysed data separately from both mothers and fathers, while $29 \%$ pooled data from both parents with no notation of parental gender. Similarly, in a recent review of fathers' participation in parenting and childhood obesity research, fathers represented $17 \%$ of parent 
participants (Davison et al., 2016). Another example of low participation rate comes from The Longitudinal Survey of Australian Children (LSAC) - a nation-wide, population-based cohort study. Although both parents are engaged wherever possible, one parent is nominated as 'Parent 1' and answers the majority of questions about the study child. In more than $95 \%$ of cases, this is the child's mother (Australian Institute of Family Studies, 2017).

Furthermore, the important issue of under-representation of single fathers in research is also highlighted in the LSAC cohort study, with only $3 \%$ of single parents in the sample being fathers (Australian Institute of Family Studies, 2017).

Taken together, these studies highlight that fathers are underrepresented in research and that important opportunities to capture their experiences and contribution to parenting and family health research is missed. There is a need to better understand the reasons why fathers are underrepresented and how their engagement and participation in research can be maximised. This raises the following questions: How do fathers respond when they are invited to participate as 'parents' in research? And what type of recruitment strategies would better engage fathers to achieve larger, broader, more representative samples?

To begin to answer some of these questions, we report data and learnings from a study that aimed to recruit Australian mothers and fathers online to investigate how parents juggle work and family-care responsibilities. We compare Facebook advertising campaigns aimed at 'parents' versus 'father-specific' options. Initially, we conducted advertising campaigns intended to be gender-neutral - using language such as 'are you a working parent?' It was expected that these gender-neutral campaigns would recruit a substantial number of fathers (as well as mothers). However, the proportion of fathers recruited was extremely poor and 
thus we conducted a second group of father-specific campaigns specifically targeting fathers (i.e. 'calling all dads...'). The aims of this brief report are to: (a) report on the proportion of fathers (and mothers) recruited in response 11 Facebook advertising campaigns, (b) consider the range of possible reasons for the lack of representation of fathers in the gender-neutral campaigns, and (c) describe the characteristics of fathers (i.e., age, single fathers, socioeconomic status) who were eventually recruited. In addition, we briefly describe the financial costs associated with online recruitment given this method is increasingly being used to target hard-to-reach populations such as fathers (Lane, Armin, \& Gordon, 2015; Thornton et al., 2016).

\section{Methods}

\section{Procedure}

Participants were recruited online from August to November 2016 for the Families at Work survey, which investigated how parents manage work and family responsibilities (see Bennetts et al. 2019 for full details of the recruitment methodology). Paid recruitment involved running 11 Facebook advertising campaigns using Facebook's 'Adverts Manager'. These campaigns were comparable in the number of images presented (single images); length of campaign (one week), the time the advertising was scheduled (i.e. 12-2pm and 6-10pm to focus outside of employment hours) and the general text used in the advertisements. The 11 campaigns all targeted employed parents of children ( $\leq 18$ years), residing in Australia (i.e. in Facebook's 'target audience' settings we selected 'parents' and 'Australia' in the demographics; residency and parenthood status was also confirmed in the survey). The first 5 
advertising campaigns were intended to recruit both mothers and fathers, and thus used gender-neutral/inclusive language (i.e. 'parents' in 2 campaigns; 'mums and dads' in 3 campaigns) and no specific gender was selected in Facebook's 'target audience' settings. The remaining 6 advertising campaigns were intended to only recruit fathers and thus fatherspecific language was used and 'male' was selected in Facebook's 'target audience' settings. All advertisements used the phrase:

“Are you a working parent/dad/mum or dad? Complete La Trobe University's 15-minute survey about work and family." All advertisements mentioned a prize draw (a chance to win 1 of $10 \$ 50$ gift cards). Individuals who 'clicked' on the advertisement were redirected to the online survey designed using Qualtrics, which took $\sim 15$ minutes to complete. Repeated participation was prevented using a Qualtrics function that places a cookie on the respondent's browser when a survey is submitted, preventing survey re-takes. Ethical approval to conduct this study was granted by La Trobe University College of Science Health and Engineering Human Ethics Sub-Committee (SHE-CHESC Reference number: S16-112; 27/07/2016) (details removed for blind peer review).

\section{Measures}

Information recorded for each advertising campaign included:

(a) the specific language used - 'parents', 'mums and dads', or just 'dads'; (b) the type of image used (e.g. father and son; family of four); (c) the total number of participants recruited/consented to participate in the survey; (d) sample characteristics including sex 
(proportion of males and females), age, marital status, number of children, socio-economic status and occupation type; and (e) the advertising cost per person recruited.

\section{Statistical analyses}

Descriptive information was summarised for each of the 11 advertising campaigns based on the measures recorded. Summary statistics were then aggregated for the campaigns targeting 'parents', 'mothers and fathers' and 'fathers only'.

\section{Results}

Sample characteristics for fathers

In total, 1468 fathers were recruited using the 11 Facebook advertising campaigns; of which 1441 (98.2\%) were recruited through the six father-specific campaigns Fathers were on average aged 40.91 years $(\mathrm{SD}=7.31)$, with $44.2 \%$ having completed a tertiary qualification, $12.9 \%$ in the most socio-economically advantaged decile based on postcode of residence, $59.8 \%$ in professional or managerial positions, and $87.3 \%$ in permanent employment. The average number of hours worked per week was $45.3(\mathrm{SD}=11.9)$ and, 149 out of $1441(10.3 \%)$ were single fathers.

Descriptive information by campaign type (including the \% of fathers vs. mothers recruited)

Table 1 presents the descriptive information for the 11 campaigns, of which two targeted 'parents'; three targeted 'mums and dads'; and six targeted 'dads' specifically. For the two campaigns that targeted 'parents', the image used showed a father with his young child. These campaigns recruited 596 participants (average cost \$1.29 per participant); 
however only three were fathers $(0.01 \%)$. For the three campaigns that targeted 'mums and dads', images included a mother and her three children, a father and son, and a mother and son. These campaigns recruited 1143 participants (average cost $\$ 0.90$ per participant); but only 24 were fathers $(2.10 \%)$. For the six campaigns that targeted fathers, images of a father and his child or children were used. These campaigns had marginally lower participant recruitment in each campaign (range 69-479), but were still very low cost (average cost $\$ 2.75$ per participant ). As would be expected, campaigns targeted solely at fathers, recruited nearly $100 \%$ males $(n=1441)$, with a small number who did not identify as male $(2.90 \%$ - who were presumably recruited when fathers 'shared' 'liked' or 'tagged' the link on Facebook).

\section{INSERT TABLE 1}

\section{Discussion}

In the current study, gender-neutral Facebook advertising campaigns were not successful at recruiting fathers to participate in parenting research. Facebook advertisements targeting 'parents' to participate yielded samples of mothers (>99\%). Even when the advertisement image was of a father with a child (e.g. campaigns 1 and 2), these images did not result in more fathers participating (an avenue that could be explored more systematically in future research). Similarly, advertisements inviting both 'mums and dads' resulted in low recruitment of fathers ( $<3 \%$ for each campaign). Conversely, advertisements targeting 'dads only' were far more effective at recruiting fathers with $\sim 98 \%$ for each of these campaigns. 
There are two main possibilities for why the online gender-neutral advertisements were unsuccessful at recruiting fathers. The first relates to the language used in the ads, and who relates to the terms 'parents' and/or 'mothers and fathers'. One possibility is that fathers saw the Facebook advertisements, but the gender-inclusive language regarding parenting and parenting roles (e.g. parents, mothers and fathers) did not engage them. The language may have reinforced persistent embedded social and gendered norms about mothers' responsibility for children/parenting. Our findings suggests that methods of stratification, with fathers targeted/named as a specific sub-sample, are necessary. This is consistent with the extant literature which has reported that explicit invitations for fathers to participate in research are often required (Bayley, Wallace, \& Choudhry, 2009; Davison et al., 2017).

An alternate explanation centres on the online recruitment process and to 'whom' Facebook posted the advertisements. In the gender-neutral advertisements, we selected 'parents' in the 'target audience' options for advertising. In making this selection, we assumed that Facebook would present the advertisements to mothers and fathers, however, this not likely to have occurred. Mothers are more intensive users of Facebook compared to fathers, including for parenting-related content (Duggan, Lenhart, Lampe, \& Ellison, 2015) potentially biasing the results. It is likely that women were more likely to be identified as inscope for 'parenting' content compared to men by Facebook's targeting algorithms, leading to a greater proportion of mothers being shown the gender-neutral ads compared to fathers. The extent to which this occurred is difficult to determine, however it is highly likely that gendered exposure played a significant role in the lack of representation from fathers. This is an important learning for researchers considering Facebook advertising to recruit parent 
populations, but it is also reflective of 'who' is exposed to parenting content in broader society - with information and opportunities most often directed at mothers.

\section{Implications}

These results provide some useful insights into designing effective recruitment strategies to gain better representation from fathers - particularly via the use of online advertising. The first and most obvious learning is that methods of stratification, with fathers targeted as a specific sub-sample, are critical. Once fathers were specifically targeted using both language and Facebook's 'target audience' tool, recruiting fathers was relatively lowcost and time-efficient. This accords with other research examining the efficiency of online advertising (e.g. Thornton et al., 2016), although not all research has found this to be the case (e.g. Dworkin, Hessel, Gliske, \& Rudi, 2016). In our study, the efficiency of online recruitment provided the opportunity to 'iteratively update' a range of recruitment strategies and ensure our final sample was inclusive of fathers. This type of targeted and iterative stratification could also be applied to specific groups of fathers that are often underrepresented in research, including single fathers, those without tertiary education, and those in less-skilled occupations. These fathers were under-represented in our sample - in the Australian general population $\sim 18 \%$ of single parents are fathers ( $10 \%$ in the current study) and about $75 \%$ of men have not completed a Bachelor Degree ( $\sim 66 \%$ in the current study) (ABS, 2016), although these differences are in part because all fathers in the current sample were employed. The current sample of fathers also over-represented those in highly skilled occupations (59.8\%) compared to the HILDA (Household, Income, Labour Dynamics in Australia) study, which found that $38.9 \%$ of employed men aged 24-64 were in either 
Managerial or Professional positions over a 6 year period (Dinh, Strazdins \& Welsh, 2017). These findings are consistent with extant research showing that online recruitment typically engages more educated and professional samples (Thornton et al., 2016).

The findings of this study share parallels with fathers' reports of lack of engagement from 'mainstream' child health and parenting services, which they perceive to be mothercentric (Rominov et al., 2017). 'Parents', while a catch-all term and potentially perceived as 'gender-inclusive' by service providers, appears to largely reach and engage mothers (Bayley et al., 2009). This mother-centric approach is also likely reinforced in parenting and health services by a lack of staff training and experience in engaging fathers, and a time-pressured work context (i.e. only enough time to engage mothers in services).

\section{Limitations}

There are several study limitations to note. First, several aspects of the 'genderneutral' and 'father-focused' advertising campaigns were not comparable; this was in-part a function of the algorithms Facebook uses to maximise exposure and successful 'clicks' on their advertisements. In particular, the total cost spent on each individual advertising campaign varied from $\$ 316$ (campaign5) to $\$ 700$ (campaigns $7,8,9$ ). Overall, the genderneutral campaigns included a lesser overall spend than the father-focused campaigns indicating that the recruitment rate was faster for mothers than for fathers. This may reflect that fathers need more time (or multiple views) to respond actively to research participation opportunities than mothers. The difference in cost per campaign also means that it is important to compare proportions of mothers/fathers recruited, and cost per consent - which 
adjusts for total audience reach - rather than absolute numbers.) Second, recruitment via social media can include 'snowballing' whereby participants 'like' or 'share' the link with friends and family who share similar characteristics and life circumstances, which may be a problem when research is seeking representative samples. Similarly, it should be noted that there was a small amount of non-paid recruitment that occurred concurrent to the Facebook advertising campaigns (e.g. cross-posting, posting on free forums), which may have affected the final numbers (and mothers/fathers) recruited. However, most of this free advertising took place prior to the paid advertisements commencing and thus is unlikely to have had a significant impact.

Overall, it is important to remember that the researcher only has partial control over who receives an advertisement via Facebook. This is of note for future researchers using social media as a parent-engagement platform. We are also mindful that some extant research has raised concerns about multiple submissions and fraudulent information when participants are recruited online (Quach et al., 2013), although this was not a problem in the current study (i.e. a cookie was used to prevent the survey being taken again through the same browser). Despite these limitations, the key finding overwhelmingly stands - very few men were recruited when the advertisements were targeted broadly at 'parents' and 'mums and dads'.

\section{$\underline{\text { Conclusions }}$}

Iterative online recruitment via social media platforms like Facebook can provided large, community-based samples that include both fathers and mothers at low cost. However, recruitment adopting gender-neutral language inclusive of all 'parents' and 'mums and dads' 
is not sufficient to ensure adequate representation from fathers - instead father-focused language and specific selection is needed to target and engage fathers. This short report contributes new evidence about ways to specifically engage and recruit fathers in contemporary parenting research, with the broader aim of redressing long held entrenchment of ideas that 'mother' equates to 'parent'. The findings are potentially generalizable to the engagement of fathers in child and parenting services and interventions.

\section{Acknowledgements}

Please see cover letter. Acknowledgements are removed in this version of the manuscript for blind peer review.

\section{References}

Australian Bureau of Statistics (ABS). (2016). Census QuickStats. Canberra. Australia. Retrieved from: http://www.censusdata.abs.gov.au/census services/getproduct/census/2016/quickstat/036

Australian Institute of Family Studies (AIFS). (2017). The Longitudinal Study of Australian Children Annual Statistical Report 2016. Australia. Retrieved from: https://data.growingupinaustralia.gov.au/pubs/asr/2016/LSAC-ASR-2016-Book.pdf

Bayley, J., Wallace, L. M., \& Choudhry, K. (2009). Fathers and parenting programmes: barriers and best practice. Community Practitioner, 82(4), 28-32.

Bennetts, S. K., Hokke, S., Crawford, S, ....Cooklin A.R. (2016). Using paid and free Facebook methods to recruit Australian parents to an online survey: An Evaluation. Journal of Medical Internet Research, 21.3: e11206.

This article is protected by copyright. All rights reserved. 
Berlyn, C., Wise, S., \& Soriano, G. (2008). Engaging fathers in child and family services: Participation, perceptions and good practice. Family Matters, 80, 37-42.

Cabrera, N. J., Volling, B. L., \& Barr, R. (2018). Fathers Are Parents, Too! Widening the Lens on Parenting for Children's Development. Child Development Perspectives, 12(3), 152-157.

Davison, K., Charles, J., Khandpur, N., \& Nelson, T. (2017). Fathers' perceived reasons for their underrepresentation in child health research and strategies to increase their involvement. Maternal and Child Health Journal, 21(2), 267-274.

Davison, K. K., Gicevic, S., Aftosmes-Tobio, A., Ganter, C., Simon, C. L., Newlan, S., \& Manganello, J. A. (2016). Fathers' representation in observational studies on parenting and childhood obesity: A systematic review and content analysis. American Journal of Public Health, 106(11), e14e21.

Dinh, H., Strazdins, L., \& Welsh, J. (2017). Hour-glass ceilings: Work-hour thresholds, gendered health inequities. Social Science \& Medicine. 176, $42-51$.

Duggan, M., Lenhart, A., Lampe, C., \& Ellison, N. (2015). Parents and Social Media. Pew Research Centre. Retrieved from: http://www.pewinternet.org/2015/07/16/parents-and-social-media/

Dworkin, J., Hessel, H., Gliske, K., \& Rudi, J. H. (2016). A comparison of three online recruitment strategies for engaging parents. Family Relations, 65(4), 550-561.

Flouri, E., \& Buchanan, A. (2003). The role of father involvement in children's later mental health. Journal of Adolescence, 26(1), 63-78.

Gatrell, C. J., Burnett, S. B., Cooper, C. L., \& Sparrow, P. (2015). The price of love: The prioritisation of childcare and income earning among UK fathers. Families, Relationships and Societies, 4(2), 225238.

Giallo, R., Dunning, M., \& Gent, A. (2017). Attitudinal barriers to help-seeking and preferences for mental health support among Australian fathers. Journal of Reproductive and Infant Psychology, 35(3), 236-247.

Lane, T. S., Armin, J., \& Gordon, J. S. (2015). Online recruitment methods for web-based and mobile health studies: a review of the literature. Journal of Medical Internet Research, 17(7). doi: 10.2196/jmir.4359

Morgan, P. J., Lubans, D. R., Callister, R., Okely, A. D., Burrows, T. L., Fletcher, R., \& Collins, C. E. (2011). The 'Healthy Dads, Healthy Kids' randomized controlled trial: efficacy of a healthy lifestyle program for overweight fathers and their children. International Journal of Obesity, 35(3), 436-447.

Panter-Brick, C., Burgess, A., Eggerman, M., McAllister, F., Pruett, K., \& Leckman, J. F. (2014). Practitioner Review: Engaging fathers-recommendations for a game change in parenting interventions based on a systematic review of the global evidence. Journal of Child Psychology and Psychiatry, 55(11), 1187-1212. 
Quach, S., Pereira, J. A., Russell, M. L., ... Kwong, J. (2013). The good, bad, and ugly of online recruitment of parents for health-related focus groups: lessons learned. Journal of Medical Internet Research, 15(11). doi:10.2196/jmir.2829

Rominov, H., Giallo, R., Pilkington, P. D., \& Whelan, T. A. (2018). Getting help for yourself is a way of helping your baby: Fathers' experiences of support for mental health and parenting in the perinatal period. Advanced online publication: Psychology of Men and Masculinity, 19(3), 457-468.

Sarkadi, A., Kristiansson, R., Oberklaid, F., \& Bremberg, S. (2008). Fathers' involvement and children's developmental outcomes: a systematic review of longitudinal studies. Acta Paediatrica, 97(2), 153-158.

Thornton, L., Batterham, P. J., Fassnacht, D. B., Kay-Lambkin, F., Calear, A. L., \& Hunt, S. (2016). Recruiting for health, medical or psychosocial research using Facebook: Systematic review. Internet Interventions, $4,72-81$.

Widarsson, M., Engström, G., Tydén, T., Lundberg, P., \& Hammar, L. M. (2015). Paddling upstream: Fathers' involvement during pregnancy as described by expectant fathers and mothers. Journal of Clinical Nursing, 24(7-8), 1059-1068.

\section{Tables}


Table 1. Details of Facebook advertisement, recruitment numbers, and costs.

\begin{tabular}{llllll}
\hline $\begin{array}{l}\text { Campaign (no), } \\
\text { Focus/Language }\end{array}$ & Image used & Total N* & $\begin{array}{l}\text { Cost per } \\
\text { campaign } \mathbf{( \$ ) * ~}\end{array}$ & Male n (\%) & $\begin{array}{l}\text { Cost per } \\
\text { consent }(\$)\end{array}$ \\
\hline (1) Parents & Father \& daughter & 403 & $\$ 350$ & $3(0.7)$ & 0.84 \\
(2) Parents & Father \& son & 193 & $\$ 350$ & $0(0.0)$ & 1.73 \\
(3) Mums and Dads & Mother, son, 2 daughters & 331 & $\$ 350$ & $4(1.2)$ & 1.02 \\
(4) Mums and Dads & Father \& son & 502 & $\$ 350$ & $12(2.3)$ & 0.68 \\
(5) Mums and Dads & Mother \& son & 310 & $\$ 316$ & $8(2.6)$ & 0.99 \\
(6) Dads & Father \& son & 69 & $\$ 350$ & $69(100.0)$ & 4.86 \\
(7) Dads & Father \& two sons & 181 & $\$ 700$ & $151(83.9)$ & 3.74 \\
(8) Dads & Father, son, daughter & 479 & $\$ 700$ & $477(99.6)$ & 1.41 \\
(9) Dads & Father, son, daughter & 314 & $\$ 700$ & $311(99.4)$ & 2.11 \\
(10) Dads & Father \& son & 180 & $\$ 400$ & $175(97.2)$ & 2.13 \\
(11) Dads & Father \& son & 261 & $\$ 604$ & $258(98.9)$ & 2.24 \\
\hline
\end{tabular}

Notes: * The total numbers/participants recruited in each campaign are presented, however these numbers are not directly comparable between campaigns as different amounts were spent, resulting in differing levels of 'reach' on Facebook. Cost per consent is a more appropriate metric for comparing the effectiveness of overall recruitment between campaigns. Average cost of consent: 'parents' was $\$ 1.29$; 'mums and dads' was $\$ 0.90$; 'dads' was \$2.75.The chronological order in which campaigns were shown via Facebook differs from the order shown above (i.e. : Campaign 1-11 were shown in the following order: $2^{\text {nd }} ; 4^{\text {th }} ; 7^{\text {th }} ; 8^{\text {th }} ; 10^{\text {th }} ; 1^{\text {st }} ; 3^{\text {rd }} ; 5^{\text {th }} ; 6^{\text {th }} ; 9^{\text {th }}$ $; 11^{\text {th }}$. 


\section{University Library}

\section{- M M N E R VA A gateway to Melbourne's research publications}

Minerva Access is the Institutional Repository of The University of Melbourne

Author/s:

Leach, LS;Bennetts, SK;Giallo, R;Cooklin, AR

Title:

Recruiting fathers for parenting research using online advertising campaigns: Evidence from an Australian study

Date:

2019-07-22

Citation:

Leach, L. S., Bennetts, S. K., Giallo, R. \& Cooklin, A. R. (2019). Recruiting fathers for parenting research using online advertising campaigns: Evidence from an Australian study. CHILD CARE HEALTH AND DEVELOPMENT, 45 (6), pp.871-876. https://doi.org/10.1111/ cch.12698.

Persistent Link:

http://hdl.handle.net/11343/286899 